\title{
Antioxidative effects of diallyl trisulfide on hydrogen peroxide- induced cytotoxicity through regulation of nuclear factor-E2-related factor-mediated thioredoxin reductase 1 expression in $\mathrm{C} 2 \mathrm{C} 12$ skeletal muscle myoblast cells
}

\author{
Ji Sook Kang ${ }^{1}$, Gi-Yiung Kim², Byung Woo Kim ${ }^{1,3}$, and Yung Hyun Choi ${ }^{1,4}$ \\ ${ }^{1}$ Anti-Aging Research Center and Blue-Bio Industry RIC, Dongeui University, 176 Eomgwangno Busanjin-gu, Busan 614-714, \\ Republic of Korea \\ ${ }^{2}$ Laboratory of Immunobiology, Department of Marine Life Sciences, Jeju National University, Jeju 690-756, Republic of \\ Korea \\ ${ }^{3}$ Department of Life Science and Biotechnology, College of Natural Sciences \& Human Ecology, Dongeui University, Busan \\ 614-714, Republic of Korea \\ ${ }^{4}$ Department of Biochemistry, Dongeui University College of Korean Medicine, 52-57, Yangjeong-ro, Busanjin, Busan \\ 614 052, Republic of Korea
}

\begin{abstract}
Diallyl trisulfide (DATS) is one of the major sulfur-containing compounds in garlic oil. In this study, we analyzed the effects of DATS against hydrogen peroxide $\left(\mathrm{H}_{2} \mathrm{O}_{2}\right)$-induced oxidative stress in C2C12 myoblasts. DATS preconditioning significantly attenuated $\mathrm{H}_{2} \mathrm{O}_{2}$-induced growth inhibition and DNA damage, as well as apoptosis by decreasing the generation of ROS. Treatment with DATS alone effectively upregulated the expression of nuclear factor-erythroid 2-related factor 2 (Nrf2) and thioredoxin reductase 1 (TrxR1), which was associated with the increased phosphorylation of Nrf2. However, the protective effects of DATS against $\mathrm{H}_{2} \mathrm{O}_{2}$-induced growth reduction and ROS accumulation were significantly abolished by auranofin, an inhibitor of TrxR activity. Moreover, DATS-mediated phosphorylation of Nrf2 and induction of TrxR1 were markedly reduced by genetic silencing of Nrf2. DATS treatment also induced the phosphorylation extracellular signal-regulating kinase (ERK), and analysis using specific inhibitors of cellular signaling pathways demonstrated that only ERK activation was involved in Nrf2 phosphorylation and TrxR1 induction. In addition, the cytoprotective potentials were abrogated in C2C12 cells pretreated with an ERK specific inhibitor. The results demonstrate that DATS protects against oxidative stress-induced DNA damage and apoptosis in $\mathrm{C} 2 \mathrm{C} 12$ cells in part through the activation of Nrf2-mediated TrxR1 induction via the ERK signaling pathway.
\end{abstract}

Key words: DATS - Oxidative stress - Nrf2 - TrxR1 - ERK

\section{Introduction}

Oxidative stress reflects an imbalance between the systemic manifestation of reactive oxygen species (ROS) and a biological system's ability to readily detoxify the reactive intermedi-

Correspondence to: Yung Hyun Choi, Department of Biochemistry, Dongeui University College of Korean Medicine, 52-57, Yangjeongro, Busanjin, Busan 614-052, Republic of Korea E-mail: choiyh@deu.ac.kr ates or to repair the resulting damage all components of the cell, including proteins, lipids, and DNA (Ermakov et al. 2013; Lyakhovich and Graifer 2015). Oxidative stress can cause disruptions in normal mechanisms of cellular signaling and is thought to be involved in the development of various diseases, such as cancer, neurodegenerative disease, and cardiovascular disease (Brieger et al. 2012; Dai et al. 2014). In contrast, antioxidant enzymes have been shown to have highly effective and sufficient for protecting cells against oxidative stress, and have some preventive or therapeutic effects against the 
symptoms of these diseases, particularly in those for which oxidative stress is the main cause (Mena et al. 2009). Therefore, therapeutic strategies should be focused on the reduction of free radical formation and scavenging of free radicals.

Most of the genes for encoding phase II detoxification or antioxidant enzymes are regulated via the redox-sensitive nuclear factor-erythroid 2-related factor (Nrf2) pathway (Huang et al. 2015; Silva-Palacios et al. 2016). Under unstimulated conditions, Nrf2 is kept in the cytosol bound to cytoskeleton Kelch-like ECH-associated protein 1 (Keap1), which acts as substrate adaptor for the Cul3-Rbx1 E3 ligase which ubiquitylates Nrf2 for proteasomal degradation (Jaramillo and Zhang 2013; O'Connell and Hayes 2015). Dissociation of this complex is achieved by thiol modification of Keap 1 preventing degradation and allowing newly synthesized Nrf2 to translocate into the nucleus where it binds to the antioxidant responsive element (ARE) in conjunction with other transcription factors (Jaramillo and Zhang 2013; Gan and Johnson 2014). In the nucleus, Nrf2 associates with small Maf proteins, forming heterodimers that bind to ARE to activate the transcription of enzymes involved in the cellular antioxidant defense and in phase II detoxification, such as $\mathrm{NAD}(\mathrm{P}) \mathrm{H}$ :quinone oxidoreductase 1 (NQO1), thioredoxin (Trx) 1, Trx reductase (TrxR) 1, and heme oxygenase-1 (HO-1) (Stefanson and Bakovic 2014; Cebula et al. 2015; Murakami and Motohashi 2015). Recent observations demonstrated that the regulation of Nrf2-ARE mediated gene expressions requires the activation of several signal transduction pathways, including mitogen-activated protein kinases (MAPKs), such as extracellular signalregulated kinase (ERK), c-Jun N-terminal kinase (JNK), p38 MAPK, phosphatidylinositol 3-kinase (PI3K)/protein kinase $\mathrm{B}(\mathrm{PKB}, \mathrm{Akt})$, and nuclear factor kappa-B (NF- $\mathrm{B})$ (Jeong et al. 2006; Li et al. 2007; Hamdulay et al. 2010; Paine et al. 2010). They are important enzymes involved in the transduction of various signals from the cell surface to the nucleus associated with the modulation of ARE-driven gene expression via Nrf2 activation. Therefore, genes regulated by an ARE encode proteins that help to control cellular redox status and protect cells from oxidative damage.

Garlic (Allium sativam L.) is a plant commonly used for seasoning food in many different cultures, particularly in Asian countries, and an important component in the complementary and alternative medicine (Li et al. 2013; Yun et al. 2014). Recent data convincingly pointed out that garlic has a wide range of biological activities against a number of chronic diseases, including cardiovascular disorders, diabetes, infections, and other metabolic ills as well as cancer (Khatua et al. 2013; Padiya and Banerjee 2013; Trio et al. 2014). Garlic is a particularly rich source of organosulfur compounds (OSCs), and diallyl monosulfide (DAS), diallyl disulfide (DADS), and diallyl trisulfide (DATS) are the most abundant compounds in garlic oil (Lea 1996; Amagase et al.
2001; Iciek et al. 2009). The antioxidant potential is in the order DATS > DADS > DAS (Chen et al. 2004; Fukao et al. 2004; Jakubíková and Sedlák 2006; Liu et al. 2014), suggesting that the number of sulfur atoms plays a vital role in the biological activities of OSCs. Recently, Liang et al. (2015) suggested that DATS acts faster as an $\mathrm{H}_{2} \mathrm{~S}$ donor compared to DADS, which also supports these results.

Although several published reports have recently described the protective effects of DATS associated with Nrf2 signaling against oxidative stress (Tsai et al. 2013; You et al. 2013; Kim et al. 2014; Xu et al. 2015), the mechanism underlying its inductive effect remains largely unknown. This study was carried out to examine the ability of DATS to protect cells from hydrogen peroxide $\left(\mathrm{H}_{2} \mathrm{O}_{2}\right)$-induced cell damage and to elucidate the mechanism underlying these protective effects using a C2C12 murine skeletal-muscle cell line.

\section{Materials and Methods}

\section{Reagents and antibodies}

DATS (allyl trisulfide, Di-2-propenyl trisulfide) was purchased from LKT Laboratories (St Paul, MN, USA). Dulbecco's modified Eagle's medium (DMEM), fetal bovine serum (FBS) and other tissue culture reagents were obtained from WelGENE Inc. (Daegu, Republic of Korea). $\mathrm{H}_{2} \mathrm{O}_{2}$, 3-(4,5-dimethylthiazol-2-yl)-2,5-diphenyltetrazolium bromide (MTT), auranofin, N-acetyl-l-cysteine (NAC), 4,6-diamidino-2-phenylindole (DAPI), and propidium iodide (PI) were purchased from Sigma-Aldrich Chemical Co. (St. Louis, MO, USA). 2',7'-dichlorofluorescein diacetate (DCFDA) and annexin V-fluorescein isothiocyanate (FITC) apoptosis detection kit were purchased from Molecular Probes (Eugene, OR, USA) and R\&D Systems Inc. (Minneapolis, MN, USA), respectively. Inhibitors of PI3K/Akt (LY294002) and MAPKs (SB203580, SP600125, and PD98058) were obtained from Calbiochem (San Diego, CA, USA). Primary antibodies were purchased from Santa Cruz Biotechnology (Santa Cruz, CA, USA) and Cell Signaling Technology (Danvers, MA, USA). Enhanced chemiluminescence (ECL) kit and horseradish peroxidase (HRP)-conjugated secondary antibodies were obtained from Amersham Life Science (Arlington Heights, IL, USA). All other chemicals not specifically cited here were purchased from Sigma-Aldrich Chemical Co.

\section{Cell culture and DATS treatment}

C2C12 cells obtained from American Type Culture Collection (Manassa, VA, USA) were maintained in DMEM supplemented with $10 \%$ fetal bovine serum (FBS) and $1 \%$ antibiotics $(100 \mathrm{U} / \mathrm{ml}$ penicillin and $100 \mu \mathrm{g} / \mathrm{ml}$ streptomycin), and incubated at $37^{\circ} \mathrm{C}$ in a water-saturated atmosphere 
of $95 \%$ ambient air and $5 \% \mathrm{CO}_{2}$. DATS was dissolved in dimethyl sulfoxide (DMSO), and adjusted to the desired final concentrations using complete culture medium.

\section{Cell viability assay and morphological imaging}

For the cell viability study, cells were grown to $70 \%$ confluence and treated with DATS in the presence or absence with other agents(s). Control cells were supplemented with complete media containing $0.1 \%$ dimethylsulfoxide (DMSO) as the vehicle control. Following treatment, cell viability was determined by use of the MTT assay, which is based on the conversion of MTT to MTT-formazan by mitochondrial enzymes. Optical density was measured at $540 \mathrm{~nm}$ with an enzyme-linked immunosorbent assay (ELISA) plate reader (Dynatech MR-7000; Dynatech Laboratories, Chantilly, VA, USA). The optical density of the formazan formed in control cells was used to represent $100 \%$ viability (Hong et al. 2016). Morphological changes of cells were monitored by obtaining photomicrographs under an inverted phase contrast microscope (Carl Zeiss, Oberkochen, Germany) with a digital camera.

\section{Lactate dehydrogenase ( $\mathrm{LDH}$ ) release assay}

The amount of LDH released from the cells in the supernatant was detected using an LDH assay kit (Sigma-Aldrich Chemical Co.) according to manufacturer's instructions. Briefly, at the end of the treatment period, culture medium was collected and transferred to new 96-well plates, then mixed with the $100 \mu \mathrm{l}$ reaction solution provided in the kit for $30 \mathrm{~min}$. The optical density was measured at $490 \mathrm{~nm}$ using an ELISA plate reader.

\section{Comet assay (Single-cell gel electrophoresis assay)}

A comet assay was performed to detect DNA migrating from single cells in the gel, following previously described method (Gunasekarana et al. 2015). Briefly, cells were exposed to $\mathrm{H}_{2} \mathrm{O}_{2}$ in the presence and absence of DATS. The cells were suspended in $1 \%$ low melting point agarose and aliquoted onto glass microscope slides. The slides were placed in single rows and electrophoresed at $30 \mathrm{~V}(1 \mathrm{~V} / \mathrm{cm})$ and $300 \mathrm{~mA}$ for 20 min to draw negatively charged DNA toward the anode. Finally, the slides were washed with $0.4 \mathrm{M}$ Tris ( $\mathrm{pH} 7.5$ ) at $4^{\circ} \mathrm{C}$ and stained with $20 \mu \mathrm{g} / \mathrm{ml}$ PI. The slides were examined under a fluorescence microscope (Carl Zeiss) and the resulting images were analyzed.

\section{Protein extraction and Western blot analysis}

Cells were harvested, washed with phosphate-buffered saline (PBS) and lysed on ice for $30 \mathrm{~min}$ in lysis buffer $(20 \mathrm{mM}$ sucrose, $1 \mathrm{mM}$ ethylenediaminetetra acetic acid, $20 \mu \mathrm{M}$ Tris- $\mathrm{HCl}, \mathrm{pH}$ 7.2, $1 \mathrm{mM}$ dithiothreitol, $10 \mathrm{mM} \mathrm{KCl}, 1.5 \mathrm{mM}$ $\mathrm{MgCl}_{2}$, and $5 \mu \mathrm{g} / \mathrm{ml}$ aprotinin). Subsequently, an equal amount of protein for each sample was separated by sodium dodecyl sulfate (SDS)-polyacrylamide gel electrophoresis and transferred to PVDF membranes (Schleicher \& Schuell, Keene, NH, USA). The membranes were blocked with $5 \%$ skim milk and then incubated overnight at $4^{\circ} \mathrm{C}$ with desired primary antibodies. The membranes were further incubated with corresponding HRP-conjugated secondary antibodies for $2 \mathrm{~h}$ at room temperature. The proteins of interest were visualized using an ECL detection system.

\section{Detection of nuclear morphological changes}

Detection of chromatin condensation and nuclear fragmentation in the nuclei of apoptotic cells was performed by DAPI staining. The cells were harvested, washed with PBS twice, and fixed with $3.7 \%$ paraformaldehyde in PBS for $10 \mathrm{~min}$ at $25^{\circ} \mathrm{C}$. The fixed cells were washed with PBS and stained with $1 \mathrm{mg} / \mathrm{ml} \mathrm{DAPI} \mathrm{solution} \mathrm{for} 10 \mathrm{~min}$. The cells were washed twice with PBS and observed by fluorescence microscopy (Zhao et al. 2014).

\section{Measurement of ROS generation}

To measure ROS levels, cells were washed twice with PBS and lysed with $1 \%$ Triton $\mathrm{X}-100$ in PBS for $10 \mathrm{~min}$ at $37^{\circ} \mathrm{C}$ and the cells then were stained with $10 \mu \mathrm{M}$ DCFDA for $20 \mathrm{~min}$ at room temperature in the dark. The green fluorescence of DCF was recorded at $515 \mathrm{~nm}$ (FL1) using a flow cytometer, and 10,000 events were counted per sample. The results were also expressed as the percentage increase relative to non-treated cells.

\section{Flow cytometrydetection of apoptosis}

The rate of apoptosis was determined using an annexin V-FITC apoptosis detection kit. After treatment with agents, the cells were stained with annexin V-FITC and PI in each sample in accordance with the manufacturer's instructions (Kwon et al. 2015). After 15 min incubation at room temperature in the dark, the degree of apoptosis was quantified as a percentage of the Annexin V-positive and PI-negative (Annexin $\mathrm{V}^{+} / \mathrm{PI}^{-}$cells) cells using a flow cytometer (Becton Dickinson, San Jose, CA, USA).

\section{siRNA transfection}

siRNA-mediated silencing of Nrf2 gene was performed using siRNA duplexes purchased from Santa Cruz Biotechnology according to the manufacturer's protocol. An unrelated siRNA with random nucleotides was used as the non-silenc- 
ing control. The siRNA was transfected into cells according to the manufacturer's instruction using the Lipofectamine 2000 Transfection Reagent (Life Technologies, Carlsbad, CA, USA). For transfection, the cells were seeded in 6-well culture plates and incubated with $50 \mathrm{nM}$ of control siRNA or Nrf2 siRNA in serum-free OPTI-MEM medium. After incubation for $6 \mathrm{~h}$, the transfection medium was replaced with fresh media containing $10 \%$ FBS for $24 \mathrm{~h}$ before further manipulation described (Choi et al. 2016).

\section{Statistical analysis}

Unless specified otherwise, data are expressed as the mean \pm standard deviation (SD) of at least three independent experiments. A one-way analysis of variance (SPSS version 12.0 software) followed by Scheffe's test was applied to determine the significance of differences between groups. A $p$ value $<0.05$ was considered significant.

\section{A}

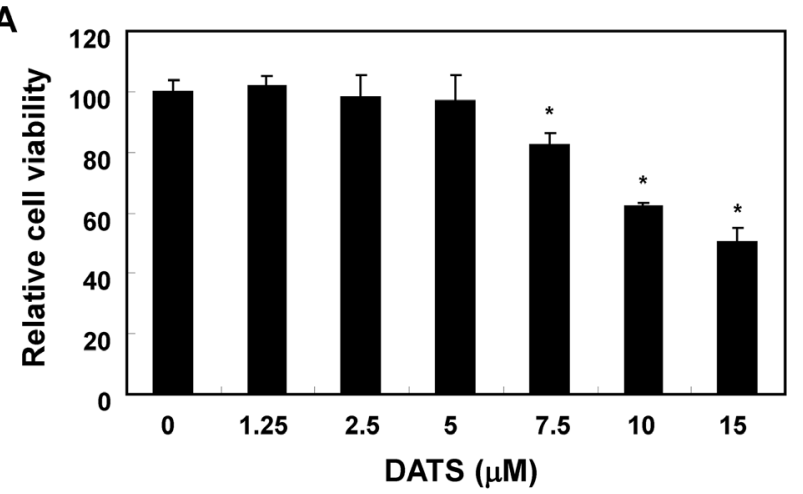

C

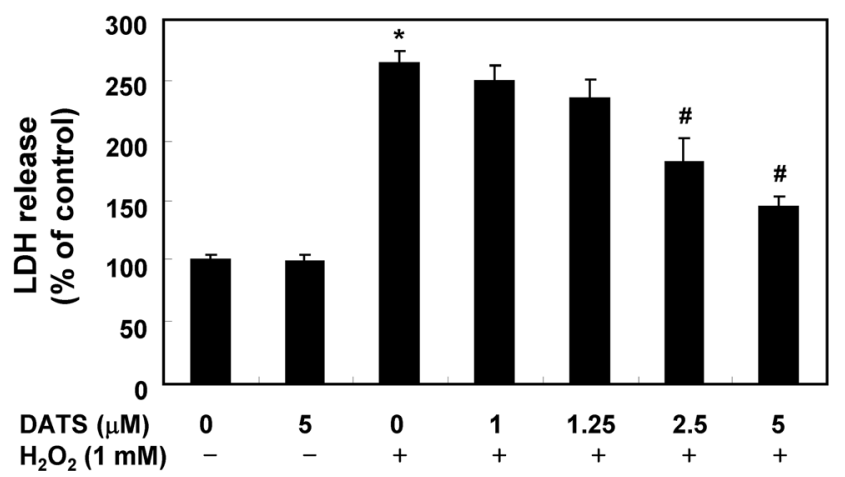

Results

\section{DATS inhibits $\mathrm{H}_{2} \mathrm{O}_{2}$-induced cytotoxicity}

C2C12 cells were treated with 1.25-15 $\mu$ M DATS for $6 \mathrm{~h}$ to determine the effect of DATS on C2C12 cell viability using a MTT assay. The treatments did not result in any cytotoxic effect up to the concentration of $5 \mu \mathrm{M}$, and cell viability dose-dependently decreased at concentrations higher than $7.5 \mu \mathrm{M}$ (Fig. 1A). DATS concentrations (less than $5 \mu \mathrm{M}$ ) were selected for the subsequent examination of the protective effect of DATS on $\mathrm{H}_{2} \mathrm{O}_{2}$-induced cytotoxicity. Treatment with $1 \mathrm{mM} \mathrm{H}_{2} \mathrm{O}_{2}$ significantly reduced cell viability about $40 \%$; this $\mathrm{H}_{2} \mathrm{O}_{2}$-induced reduction of cell viability was concentration-dependently protected by pretreatment with DATS (Fig. 1B). We also determined C2C12 cell damage by LDH assay. As shown in Fig. $1 \mathrm{C}$, the $\mathrm{H}_{2} \mathrm{O}_{2}$-treated cells exhibited an induced $\mathrm{LDH}$ release as compared with

B

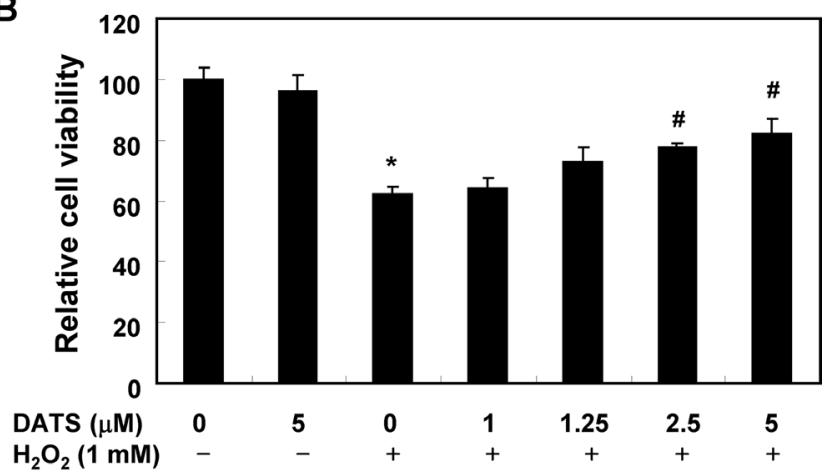

D

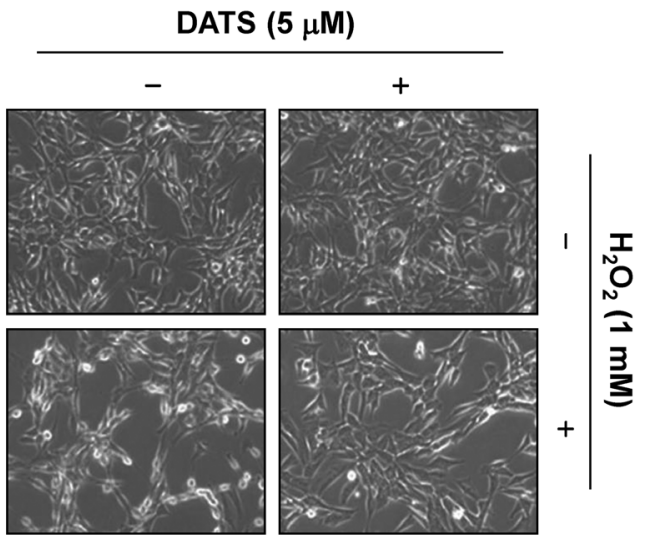

Figure 1. DATS inhibits $\mathrm{H}_{2} \mathrm{O}_{2}$-induced cytotoxicity in $\mathrm{C} 2 \mathrm{C} 12$ cells. Cells were treated with various concentrations of DATS for $6 \mathrm{~h}$ (A) or pretreated with the indicated concentrations of DATS for $1 \mathrm{~h}$ and then incubated with and without $1 \mathrm{mM} \mathrm{H}_{2} \mathrm{O}_{2}$ for $6 \mathrm{~h}(\mathbf{B})$. Cell viability was assessed using an MTT reduction assay. C. The cytotoxicity was also measured by the LDH assay. The results represent the mean \pm SD obtained in three independent experiments $\left({ }^{*} p<0.05\right.$ compared with control group; ${ }^{\#} p<0.05$ compared with $\mathrm{H}_{2} \mathrm{O}_{2}-$ treated group). D. Cellular morphological changes were monitored in photomicrographs obtained using inverted phase contrast microscopy $(\times 200)$. 
the control, whereas pretreatment of cells with DATS markedly attenuated $\mathrm{LDH}$ release in a concentration-dependent manner. In addition, $\mathrm{H}_{2} \mathrm{O}_{2}$ stimulation significantly induced morphological changes including extensive cytosolic vacuolization and the presence of irregular cell membrane buds, which were effectively attenuated by DATS pretreatment (Fig. 1D). These results indicate that DATS may protect $\mathrm{C} 2 \mathrm{C} 12$ cells from $\mathrm{H}_{2} \mathrm{O}_{2}$-induced damage.

\section{DATS protects against $\mathrm{H}_{2} \mathrm{O}_{2}$-induced DNA damage}

We next examined the effects of DATS on $\mathrm{H}_{2} \mathrm{O}_{2}$-mediated DNA damage in $\mathrm{C} 2 \mathrm{C} 12$ cells. A comet assay showed that exposure to $\mathrm{H}_{2} \mathrm{O}_{2}$ led to loss of membrane integrity, with fragmented DNA resolved outside the cell as comet-like structures; this adverse effect was markedly inhibited by DATS pretreatment (Fig. 2A). In addition, immunoblotting results indicated that treatment of $\mathrm{C} 2 \mathrm{C} 12$ cells with $\mathrm{H}_{2} \mathrm{O}_{2}$ upregulated the level of the phosphorylated histone variant $\mathrm{H} 2 \mathrm{AX}$ at serine 139 ( $\mathrm{p}-\gamma \mathrm{H} 2 \mathrm{AX})$, a sensitive marker of DNA double-strand breaks (Rogakou et al. 1998) (Fig. 2C). Pretreatment with DATS significantly reduced $\mathrm{H}_{2} \mathrm{O}_{2}$-induced $\mathrm{p}-\gamma \mathrm{H} 2 \mathrm{AX}$ expression.

\section{DATS protects against $\mathrm{H}_{2} \mathrm{O}_{2}$-induced apoptosis}

To evaluate the potential effect of DATS on $\mathrm{H}_{2} \mathrm{O}_{2}$-induced $\mathrm{C} 2 \mathrm{C} 12$ cell apoptosis, we examined apoptotic features by measuring the chromatin condensation of the nuclei and poly(ADP-ribose) polymerase (PARP) cleavage. DAPI staining revealed increased nuclei with chromatin condensation and the formation of apoptotic bodies, which are characteristic morphological changes of apoptosis, in cells cultured with $\mathrm{H}_{2} \mathrm{O}_{2}$. However, the control and

A

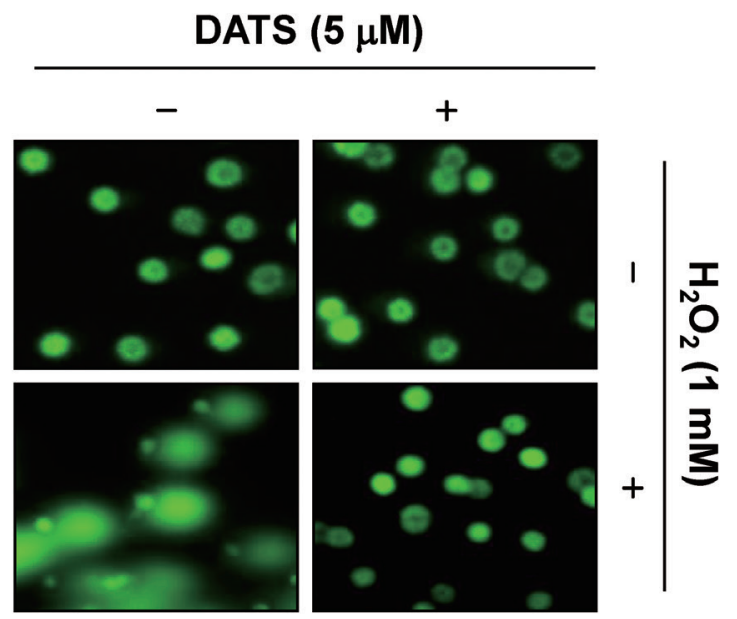

C

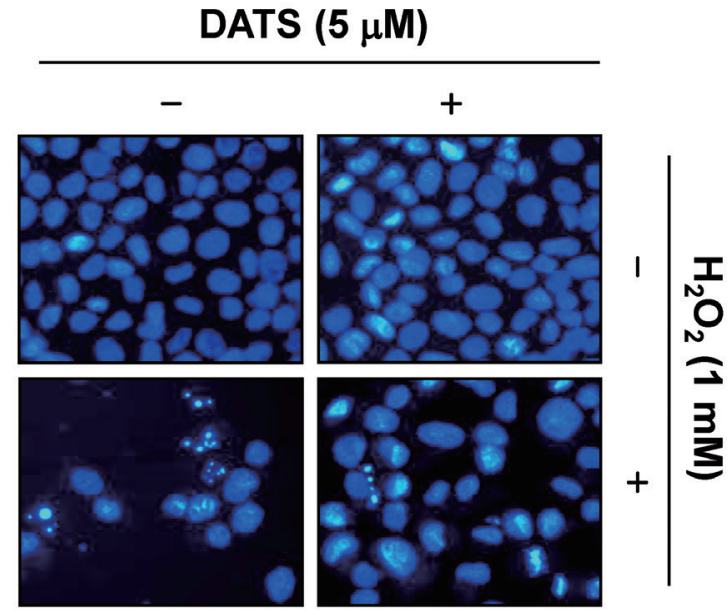

B

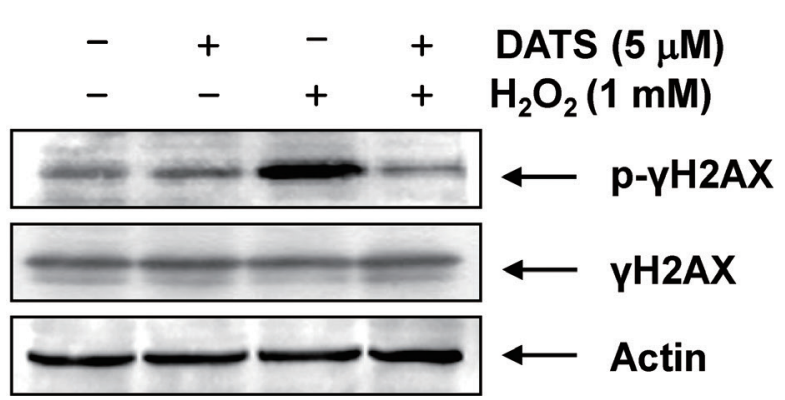

D

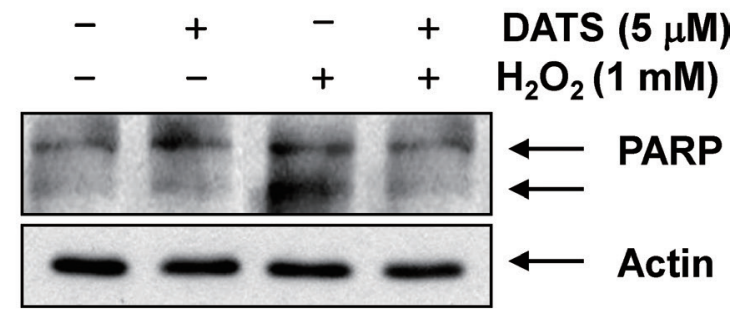

Figure 2. Inhibition of $\mathrm{H}_{2} \mathrm{O}_{2}$-induced DNA damage and apoptosis by DATS in C2C12 cells. Cells were pretreated with $5 \mu \mathrm{M}$ DATS for $1 \mathrm{~h}$ and then incubated with and without $1 \mathrm{mM} \mathrm{H}_{2} \mathrm{O}_{2}$ for $6 \mathrm{~h}$. A. To detect cellular DNA damage, the comet assay was performed and representative pictures of the comets were taken using fluorescence microscopy ( $\times 200$ original magnification). C. The cells were fixed and stained with DAPI. The stained nuclei were observed using fluorescent microscopy ( $\times 400$ original magnification). B., D. The cells were lysed and equal amounts of cell lysate $(50 \mu \mathrm{g})$ were separated by SDS-PAGE and transferred to nitrocellulose membranes. The membranes were probed with specific antibodies against $\mathrm{p}-\gamma \mathrm{H} 2 \mathrm{AX}, \gamma \mathrm{H} 2 \mathrm{AX}, \mathrm{PARP}$, and actin (the latter as an internal control) and the proteins were visualized by ECL. 
DATS alone treated groups showed few apoptotic cells, and pretreatment of the cells with DATS significantly abrogated $\mathrm{H}_{2} \mathrm{O}_{2}$-induced apoptotic characteristics (Fig. 2C). Immunoblotting results also indicated that there was a marked increase in the level of cleaved PARP, a protein marker of apoptosis, in $\mathrm{H}_{2} \mathrm{O}_{2}$-treated cells compared with the control; treatment with DATS significantly decreased this cleavage (Fig. 2D).

\section{DATS reduces $\mathrm{H}_{2} \mathrm{O}_{2}$-induced $\mathrm{ROS}$ generation}

Intracellular ROS generation was monitored by flow cytometry to investigate whether DATS could prevent $\mathrm{H}_{2} \mathrm{O}_{2}$ induced ROS generation. Significantly increased ROS level was detected after $1 \mathrm{mM} \mathrm{H}_{2} \mathrm{O}_{2}$ treatment unlike in untreated

A

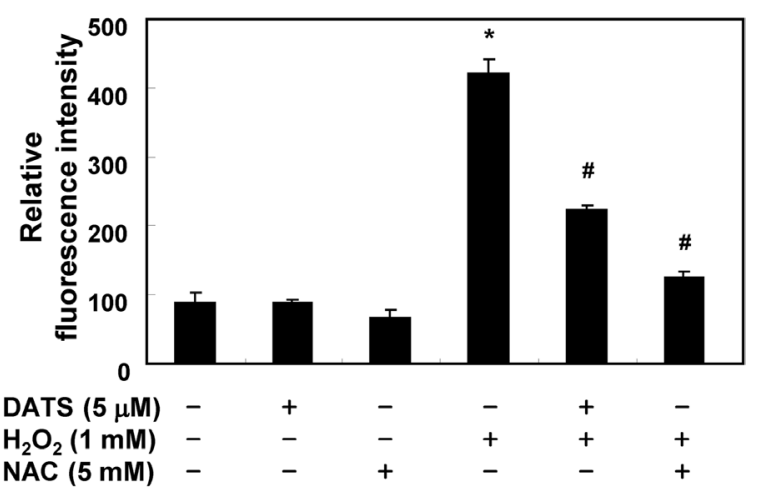

B

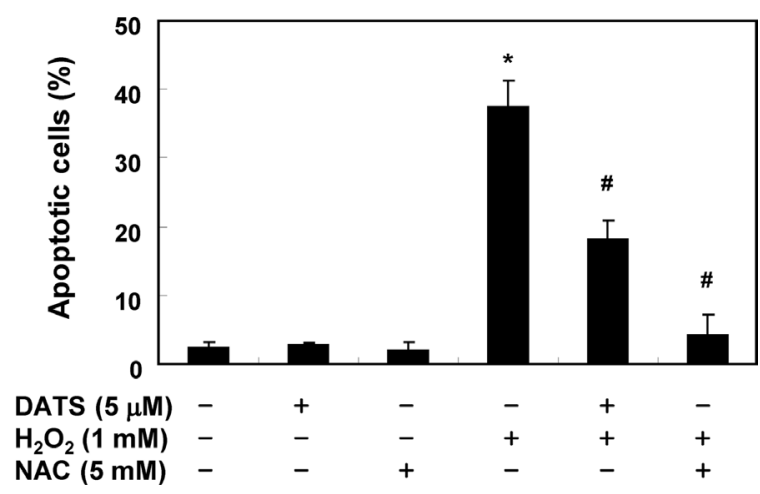

Figure 3. Inhibition of $\mathrm{H}_{2} \mathrm{O}_{2}$-induced ROS generation and apoptosis by DATS in C2C12 cells. Cells were pretreated with $5 \mu \mathrm{M}$ DATS for $1 \mathrm{~h}$ and then incubated with or without $1 \mathrm{mM} \mathrm{H}_{2} \mathrm{O}_{2}$ for $6 \mathrm{~h}$. A. To monitor ROS production, the cells were incubated at $37^{\circ} \mathrm{C}$ in the dark for 20 min with new culture medium containing $10 \mu \mathrm{M}$ DCFDA. ROS accumulation was measured using flow cytometry. B. To quantify the degree of apoptosis, the cells were stained with annexin-V-FITC and PI for flow cytometry analysis. The results are the mean \pm SD obtained in three independent experiments $\left({ }^{*} p<\right.$ 0.05 compared with the control group; ${ }^{\#} p<0.05$ compared with the $\mathrm{H}_{2} \mathrm{O}_{2}$-treated group). cells; however, this increase was significantly reduced in the presence of $5 \mu \mathrm{M}$ DATS (Fig. 3A). As a positive control, the ROS scavenger NAC ( $5 \mathrm{mM})$ also markedly attenuated $\mathrm{H}_{2} \mathrm{O}_{2}$-induced ROS generation and DATS itself did not contribute to the ROS generation, indicating that DATS scavenged $\mathrm{H}_{2} \mathrm{O}_{2}$-induced ROS accumulation. Flow cytometry analysis revealed increased number of annexin-positive cells in the $\mathrm{H}_{2} \mathrm{O}_{2}$-treated $\mathrm{C} 2 \mathrm{C} 12$ cells compared to that in the control group. In contrast, the treatment of cells with DATS prior to $\mathrm{H}_{2} \mathrm{O}_{2}$ exposure protected the $\mathrm{C} 2 \mathrm{C} 12$ cells against apoptosis (Fig. 3B).

\section{Cytoprotective effect of DATS against oxidative stress is mediated through TrxR1 induction}

To determine whether that the protective effects of DATS against $\mathrm{H}_{2} \mathrm{O}_{2}$-induced oxidative stress and apoptosis result from the induction of antioxidant genes, such as TrxR1, NQO-1, and HO-1, and their transcription factor Nrf2 and Keap1, a repressor of Nrf2, Western blot analyses were performed. DATS enhanced TrxR1 expression, but not Keap1, NQO-1 and HO-1, in time- and concentration-dependent manners; the enhanced expression was associated with increased expression and phosphorylation of Nrf2 (Fig. 4). Therefore, C2C12 cells were pre-treated with auranofin, which is widely used as an inhibitor of TrxR activity (Liu et al. 2000; Roder and Thomson 2015), in the presence or absence of DATS and then exposed to $\mathrm{H}_{2} \mathrm{O}_{2}$, to identify whether the TrxR is involved in the protective effect of DATS. Auranofin significantly abrogated the protective effect of DATS on
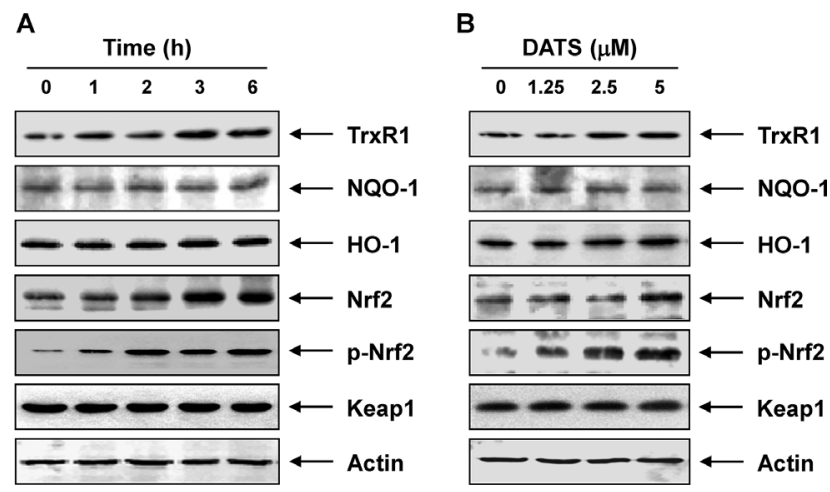

Figure 4. Effects of DATS on the expression of Nrf2, TrxR1, NQO1, and HO-1 in C2C12 cells. Cells were incubated with $5 \mu \mathrm{M}$ DATS for the indicated periods (A) or incubated for $6 \mathrm{~h}$ with the indicated concentrations of DATS (B). Cellular proteins were separated by SDS-PAGE and transferred to nitrocellulose membranes. The membranes were probed with the indicated antibodies. Proteins were visualized using ECL. Actin was used as an internal control. 
$\mathrm{H}_{2} \mathrm{O}_{2}$-induced reduction of cell viability and production of ROS (Fig. 5).

\section{DATS upregulates TrxR1 expression via Nrf2 activation}

To clarify the role of Nrf2 in TrxR1 upregulation in C2C12 cells, we developed an Nrf2 gene knockdown model using siRNA transfection. Compared to the control siRNAtransfected cells, silencing Nrf2 through a specific siRNA eliminated the DATS-induced expression of Nrf2 as well as its phosphorylation and TrxR1 induction (Fig. 6A). Moreover, the siNrf2 transfection abrogated the protective effects of DATS against $\mathrm{H}_{2} \mathrm{O}_{2}$-induced growth reduction unlike in the control siRNA-transfected cells (Fig. 6B).

\section{DATS enhances Nrf2 phosphorylation by ERK}

To investigate whether Nrf2 phosphorylation by DATS in $\mathrm{C} 2 \mathrm{C} 12$ cells might be affected by activation of signaling pathways, such as PI3K/Akt and MAPKs as upstream signaling mediators, we observed the phospho-forms of components of PI3K/Akt and MAPKs. Although the total protein levels

A

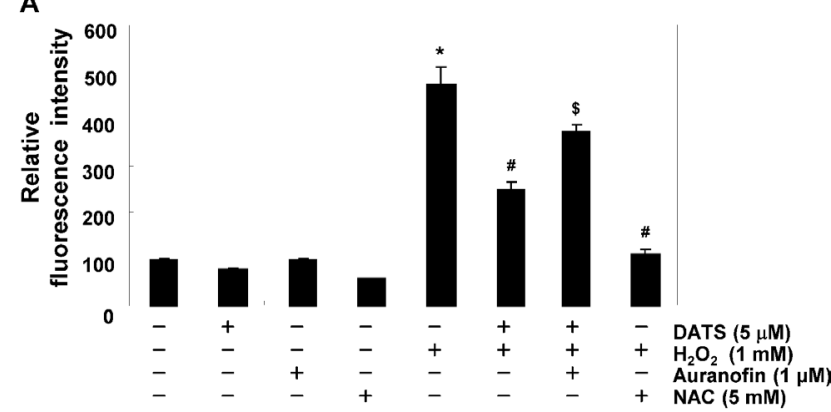

B

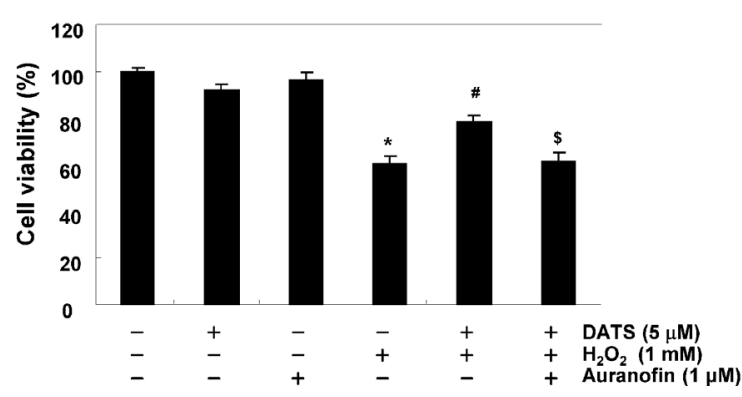

Figure 5. Effects of TrxR inhibition on DATS-mediated attenuation of growth inhibition and ROS formation by $\mathrm{H}_{2} \mathrm{O}_{2}$ in $\mathrm{C} 2 \mathrm{C} 12$ cells. Cells were pretreated for $1 \mathrm{~h}$ with $5 \mu \mathrm{M}$ DATS and then treated for $6 \mathrm{~h}$ with or without $1 \mathrm{mM} \mathrm{H} \mathrm{H}_{2} \mathrm{O}_{2}$ in the absence or presence of $1 \mu \mathrm{M}$ auranofin. ROS generation (A) and cell viability (B) were estimated. The results are the mean \pm SD values obtained in three independent experiments $\left({ }^{*} p<0.05\right.$ compared with control group; ${ }^{\#} p<0.05$ compared with $\mathrm{H}_{2} \mathrm{O}_{2}$-treated group; ${ }^{\$} p<0.05$ compared with $\mathrm{H}_{2} \mathrm{O}_{2}$ and DATS-treated group). of ERK did not show notable changes, DATS markedly increased the phosphorylation of ERK within $30 \mathrm{~min}$ of treatment, while PI3K, Akt, JNK, and p38 MAPK remained unchanged in their phosphorylation levels (Fig. 7A). The dependence of the induction and phosphorylation of Nrf2 challenged with DATS upon the activation of either ERK was proven using a specific inhibitor of ERK, PD98059. C2C12 cells were pretreated with $50 \mu \mathrm{M}$ PD98059 for $1 \mathrm{~h}$ and then treated with DATS for $6 \mathrm{~h}$. PD98059 treatment effectively reduced the DATS-induced induction and phosphorylation of Nrf2, with a resulting drop in the induction of TrxR1 (Fig. 6C). However, treatment with other specific pharmacological inhibitors of PI3K/Akt (LY294002), JNK (SP600125), and p38 MAPK (SB203580) did not affect the expression of Nrf2 and TrxR1. In addition, co-pretreatment with PD98059 and DATS prior to the $\mathrm{H}_{2} \mathrm{O}_{2}$ exposure was able to remarkably ab-

A

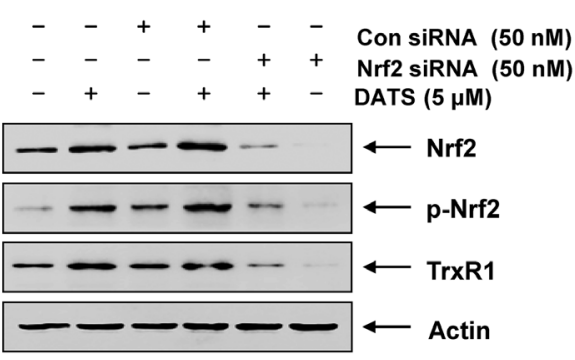

B

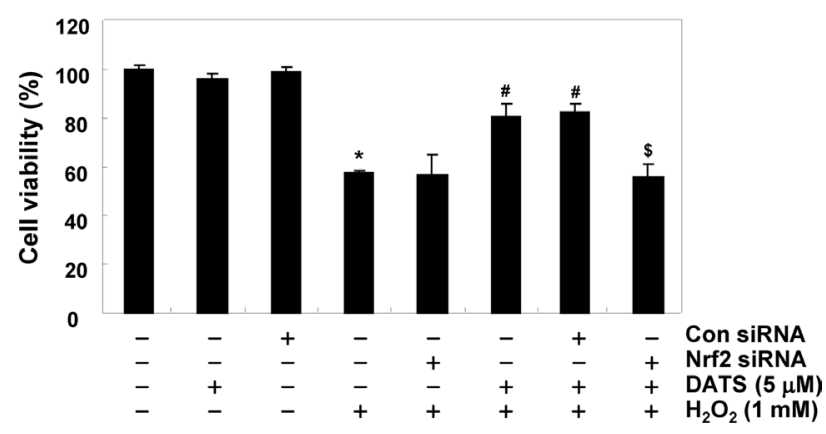

Figure 6. Nrf2-mediated induction of TrxR1 expression by DATS in $\mathrm{C} 2 \mathrm{C} 12$ cells. Cells were transfected with control (Con siRNA, as a negative control for RNA interference) and Nrf2 siRNA. After $24 \mathrm{~h}$, the cells were treated with $5 \mu \mathrm{M}$ DATS for $6 \mathrm{~h}$ (A) in the presence or absence with $1 \mathrm{mM} \mathrm{H}_{2} \mathrm{O}_{2}$ (B). A. Cellular proteins were separated by SDS-PAGE and transferred to nitrocellulose membranes. The membranes were probed with antibodies against Nrf2, p-Nrf2 and TrxR1. Proteins were visualized using ECL. Actin was used as an internal control. B. Cell viability was assessed using a MTT reduction assay. The results are the mean \pm SD values obtained in three independent experiments $\left({ }^{*} p<\right.$ 0.05 compared with control group; ${ }^{\#} p<0.05$ compared with $\mathrm{H}_{2} \mathrm{O}_{2}$-treated group; ${ }^{\$} p<0.05$ compared with $\mathrm{H}_{2} \mathrm{O}_{2}$ and $\mathrm{Nrf} 2$ siRNA-treated group). 
A

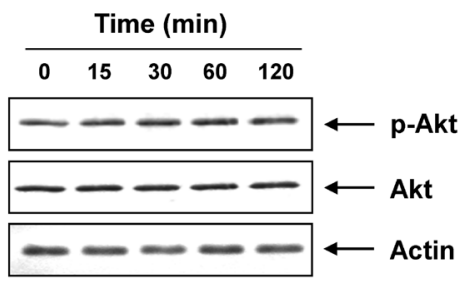

B

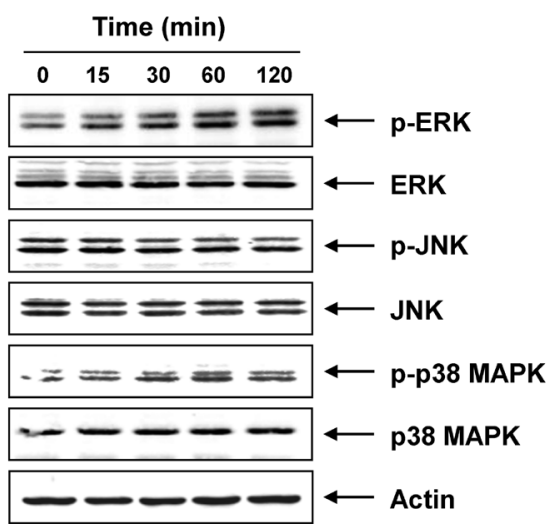

C

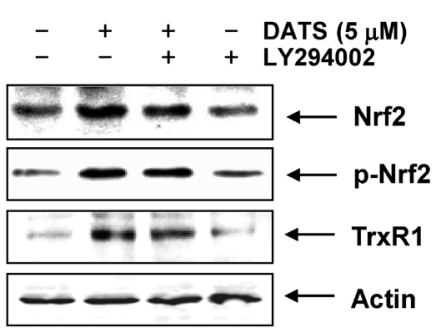

D

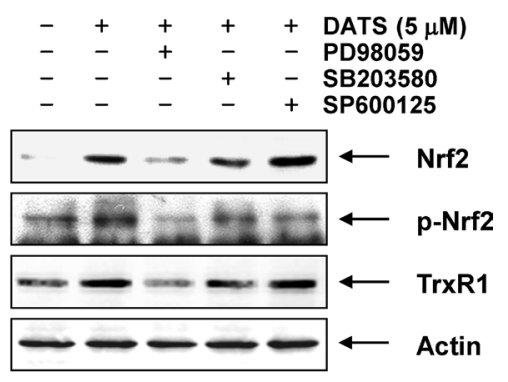

Figure 7. Involvement of ERK signaling pathway on the induction of Nrf2 and TrxR1 by DATS in C2C12 cells. Cells were treated with $5 \mu \mathrm{M}$ DATS for the indicated times $(\mathbf{A}, \mathbf{B})$ or pre-treated for $1 \mathrm{~h}$ with and without the indicated inhibitors (LY294002, a specific inhibitor of PI3K; PD98059, a specific ERK inhibitor; SB203580, a specific p38 MAPK inhibitor; SP600125, a specific JNK inhibitor), and then treated with $5 \mu \mathrm{M}$ DATS for an additional $6 \mathrm{~h}(\mathrm{C}, \mathrm{D})$. The cells were lysed, and then equal amounts of cell lysates were separated by SDSPAGE and transferred to nitrocellulose membranes. The membranes were probed with the indicated antibodies, and the proteins were visualized using ECL. Actin was used as an internal control.
A

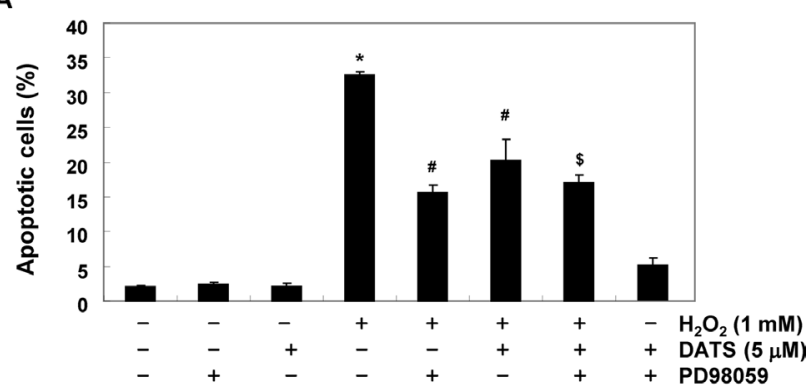

B

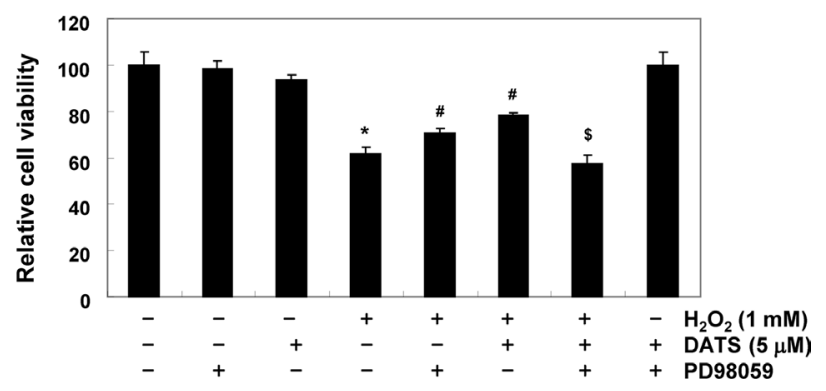

Figure 8. Effects of ERK inhibition on DATS-mediated attenuation of apoptosis and growth inhibition by $\mathrm{H}_{2} \mathrm{O}_{2}$ in $\mathrm{C} 2 \mathrm{C} 12$ cells. Cells were pretreated for $1 \mathrm{~h}$ with $5 \mu \mathrm{M}$ DATS and were subsequently treated for $6 \mathrm{~h}$ with or without $1 \mathrm{mM} \mathrm{H}_{2} \mathrm{O}_{2}$ in the absence or presence of $50 \mu \mathrm{M}$ PD98059. Apoptosis rate (A) and cell viability (B) were estimated. The results are expressed as the mean $\pm \mathrm{SD}$ values obtained in three independent experiments $\left({ }^{*} p<0.05\right.$ compared with the control group; ${ }^{\#} p<0.05$ compared with the $\mathrm{H}_{2} \mathrm{O}_{2}$-treated group; ${ }^{\$} p<0.05$ compared with the $\mathrm{H}_{2} \mathrm{O}_{2}$ and DATS treated group). rogate the protective effects of DATS against $\mathrm{H}_{2} \mathrm{O}_{2}$-induced apoptosis as well as growth reduction (Fig. 8).

\section{Discussion}

In the current study, DATS showed intracellular ROS scavenging activities and provided cytoprotection against oxidative stress in $\mathrm{C} 2 \mathrm{C} 12$ cells (Figs. 1 and $3 \mathrm{~A}$ ). DATS antagonized $\mathrm{H}_{2} \mathrm{O}_{2}$-induced DNA damage and apoptosis accompanied with a significant decrease of ROS generation (Figs. 2 and 3). These data support the view that the protective effects of DATS contribute to its role in the ROS scavenging effect and the antioxidant defense activity against $\mathrm{H}_{2} \mathrm{O}_{2}$ treatment in $\mathrm{C} 2 \mathrm{C} 12$ cells.

Accumulating evidence indicates that Nrf2 is a critical regulator in the orchestration of cellular antioxidant defenses and maintenance of redox homeostasis by mediating the induction of a variety of antioxidant defense enzymes. Nrf2 has been implicated as a therapeutic target for the prevention against oxidative stress-induced DNA damage and apoptosis (Gan and Johnson 2014; Huang et al. 2015). In addition, TrxR is a nicotinamide adenine dinucleotide phosphate (NADPH)-dependent seleno cysteine-containing flavoenzyme that catalyzes the reduction of oxidized Trx and other small molecular oxidants (Mustacich and Powis 2000; Arnér 2009). Therefore, the Trx system, a thiol-dependent electron donor system comprising Trx, TrxR, and NADPH, is critical in maintaining cellular redox homeostasis by counteracting the effects 
of ROS and regulating redox-related signaling cascades (Arnér and Holmgren 2000; Nguyen et al. 2006). The Trx system also has key roles in DNA synthesis and activation of transcription factors that regulate cell growth (Kondo et al. 2006; Holmgren and Lu 2010). The present results demonstrate that DATS treatment leads to an increase in the level of Nrf2 phosphorylation as well as the expression of $\mathrm{Nrf} 2$, and the expression of its downstream antioxidant enzyme TrxR1, but not NQO1 and HO-1, in time- and concentration-dependent manners (Fig. 4). To confirm that the protective effects of DATS were due to Trx signaling, auranofin, an inhibitor of TrxR activity (Liu et al. 2000; Roder and Thomson 2015), was used. Our data indicate that induction of TrxR1 expression might be required to suppress $\mathrm{H}_{2} \mathrm{O}_{2}$-induced ROS generation and that the antioxidative effects of DATS may occur through Trx signaling pathway (Fig. 5).

To further determine whether up-regulation of TrxR1 by DATS treatment is caused by Nrf2 pathway, we transfected cells with Nrf2 siRNA followed by treatment with DATS. Transfection with Nrf2 siRNA markedly attenuated DATS-induced TrxR1 expression compared to control along with the inhibition of Nrf2 phosphorylation (Fig. 6A), demonstrating that DATS could induce TrxR1 expression by activating Nrf2 signaling. In parallel with these observations, silencing Nrf2 reversed the protective effects of DATS against $\mathrm{H}_{2} \mathrm{O}_{2}$-induced reduction of $\mathrm{C} 2 \mathrm{C} 12$ cell viability (Fig. $6 \mathrm{~B}$ and $\mathrm{C}$ ). Therefore, we conclude that DATS treatment has a protective effect against $\mathrm{H}_{2} \mathrm{O}_{2}$-mediated oxidative stress in C2C12 cells by activating the Nrf2-mediated TrxR1 signaling pathway.

Because several cellular signaling pathways including PI3K/Akt and MAPKs represent important regulatory pathways for Nrf2 phosphorylation and nuclear translocation associated with inducible expression of antioxidant enzymes (Kweon et al. 2006; Surh et al. 2008), the effects of DATS on PI3K/Akt and MAPKs cascades were investigated to further identify the signaling pathways affected by DATS that enhance Nrf2 phosphorylation and TrxR1 expression. Immunoblotting results indicated that phosphorylation of ERK was observed at $30 \mathrm{~min}$ after DATS treatment and increased for up to $120 \mathrm{~min}$, while PI3K, Akt, JNK, and p38 MAPK kinases were not affected (Fig. 7A). Therefore, we next examined the effects of specific inhibitors of PI3K/ Akt and three MAPKs on the phosphorylation of Nrf2 as well as the increased levels of TrxR1. DATS-induced phosphorylation of Nrf2 and TrxR1 expression was markedly suppressed by PD98059, a specific inhibitor of ERK (Fig. 7B). However, other inhibitors did not dramatically affect Nrf2 phosphorylation and TrxR1 expression, implicating ERK as having the major role in Nrf2 phosphorylation in the induction of downstream TrxR1 expression in DATS-treated C2C12 cells. Importantly, blockage of ERK activation with PD98059 drastically attenuated the protective effects of DATS against $\mathrm{H}_{2} \mathrm{O}_{2}$-induced apoptosis and inhibition of the growth in $\mathrm{C} 2 \mathrm{C} 12$ cells (Fig. 8). Taken together, these findings support the hypothesis that the ERK signaling pathway is involved in DATS-mediated activation of Nrf2 and upregulation of TrxR1. Thus, regulation of the Nrf2-mediated TrxR1 pathway can reduce $\mathrm{H}_{2} \mathrm{O}_{2}$-induced oxidative damage in $\mathrm{C} 2 \mathrm{C} 12$ cells.

In summary, our results demonstrate that DATS protects C2C12 cells against oxidative stress-induced DNA damage and apoptosis through scavenging of ROS. Elevated activation of ERK signaling appears to be responsible for the activation of Nrf2 and its subsequent induction of TrxR1 expression. Although further research and clinical trials are needed to elucidate the molecular mechanisms detected herein, we suggest that DATS is able to reduce oxidative stress and ameliorate oxidative stress-related diseases.

Acknowledgements. This research was supported by Basic Science Research Program through the National Research Foundation of Korea (NRF) grant funded by the Korea government (2015R1A2A2A01004633) and the Blue-Bio Industry Regional Innovation Center (RIC08-06-07) at Dongeui University as a RIC program under Ministry of Trade, Industry \& Energy and Busan city.

Conflict of interest. The authors have no conflict of interest to declare.

\section{References}

Amagase H., Petesch B. L., Matsuura H., Kasuga S., Itakura Y. (2001): Intake of garlic and its bioactive components. J. Nutr. 131, 955S-9562S

Arnér E. S., Holmgren A. (2000): Physiological functions of thioredoxin and thioredoxin reductase. Eur. J. Biochem. 267, 6102-6109

https://doi.org/10.1046/j.1432-1327.2000.01701.x

Arnér E. S. (2009): Focus on mammalian thioredoxin reductasesimportant seleno-proteins with versatile functions. Biochim. Biophys. Acta 1790, 495-526

https://doi.org/10.1016/j.bbagen.2009.01.014

Brieger K., Schiavone S., Miller F. J. Jr, Krause K. H. (2012): Reactive oxygen species: from health to disease. Swiss Med. Wkly. 142, w13659 https://doi.org/10.4414/smw.2012.13659

Cebula M., Schmidt E. E., Arnér E. S. (2015): TrxR1 as a potent regulator of the Nrf2-Keap1 response system. Antioxid. Redox. Signal. 23, 823-853

https://doi.org/10.1089/ars.2015.6378

Chen C., Pung D., Leong V., Hebbar V., Shen G., Nair S., Li W., Kong A. N. (2004): Induction of detoxifying enzymes by garlic organosulfur compounds through transcription factor Nrf2: effect of chemical structure and stress signals. Free Radic. Biol. Med. 37, 1578-1590

https://doi.org/10.1016/j.freeradbiomed.2004.07.021 
Choi E. O., Jeong J. W., Park C., Hong S. H., Kim G. Y., Hwang H. J., Cho E. J., Choi Y. H. (2016): Baicalein protects C6 glial cells against hydrogen peroxide-induced oxidative stress and apoptosis through regulation of the Nrf2 signaling pathway. Int. J. Mol. Med. 37, 798-806 https://doi.org/10.3892/ijmm.2016.2460

Dai D. F., Chiao Y. A., Marcinek D. J., Szeto H. H., Rabinovitch P. S (2014); Mitochondrial oxidative stress in aging and healthspan. Longev. Healthspan 3, 6 https://doi.org/10.1186/2046-2395-3-6

Ermakov A. V., Konkova M. S., Kostyuk S. V., Izevskaya V. L., Baranova A., Veiko N. N. (2013): Oxidized extracellular DNA as a stress signal in human cells. Oxid. Med. Cell. Longev. 2013, 649747 https://doi.org/10.1155/2013/649747

Fukao T., Hosono T., Misawa S., Seki T., Ariga T. (2004): The effects of allyl sulfides on the induction of phase II detoxification enzymes and liver injury by carbon tetrachloride. Food Chem. Toxicol. 42, 743-739 https://doi.org/10.1016/j.fct.2003.12.010

Gan L., Johnson J. A. (2014): Oxidative damage and the Nrf2-ARE pathway in neurodegenerative diseases. Biochim. Biophys. Acta 1842, 1208-1218 https://doi.org/10.1016/j.bbadis.2013.12.011

Gunasekarana V., Raj G. V., Chand P. (2015): A comprehensive review on clinical applications of comet assay. J. Clin. Diagn. Res. 9, GE01-5 https://doi.org/10.7860/jcdr/2015/12062.5622

Hamdulay S. S., Wang B., Birdsey G. M., Ali F., Dumont O., Evans P. C., Haskard D. O., Wheeler-Jones C. P., Mason J. C. (2010): Celecoxib activates PI-3K/Akt and mitochondrial redox signaling to enhance heme oxygenase-1-mediated anti-inflammatory activity in vascular endothelium. Free Radic. Biol. Med. 48, 1013-1023

https://doi.org/10.1016/j.freeradbiomed.2010.01.017

Holmgren A., Lu J. (2010): Thioredoxin and thioredoxin reductase: current research with special reference to human disease. Biochem. Biophys. Res. Commun. 396, 120-124 https://doi.org/10.1016/j.bbrc.2010.03.083

Hong S. H., Sim M. J., Kim Y. C. (2016): Melanogenesis-promoting effects of Rhynchosia nulubilis and Rhynchosia volubilis ethanol extracts in melana cells. Toxicol. Res. 32, 141-147 https://doi.org/10.5487/TR.2016.32.2.141

Huang Y., Li W., Su Z. Y., Kong A. N. (2015): The complexity of the Nrf2 pathway: beyond the antioxidant response. J. Nutr. Biochem. 26, 1401-1413 https://doi.org/10.1016/j.jnutbio.2015.08.001

Iciek M., Kwiecień I., Włodek L. (2009): Biological properties of garlic and garlic-derived organosulfur compounds. Environ. Mol. Mutagen. 50, 247-265 https://doi.org/10.1002/em.20474

Jakubíková J., Sedlák J. (2006): Garlic-derived organosulfides induce cytotoxicity, apoptosis, cell cycle arrest and oxidative stress in human colon carcinoma cell lines. Neoplasma 53, 191-199

Jaramillo M. C., Zhang D. D. (2013): The emerging role of the Nrf2Keap1 signaling pathway in cancer. Genes Dev. 27, 2179-2191 https://doi.org/10.1101/gad.225680.113
Jeong W. S., Jun M., Kong A. N. (2006): Nrf2: a potential molecular target for cancer chemoprevention by natural compounds. Antioxid. Redox. Signal. 8, 99-106 https://doi.org/10.1089/ars.2006.8.99

Khatua T. N., Adela R., Banerjee S. K. (2013): Garlic and cardioprotection: insights into the molecular mechanisms. Can. J. Physiol. Pharmacol. 91, 448-458 https://doi.org/10.1139/cjpp-2012-0315

Kim S., Lee H. G., Park S. A., Kundu J. K., Keum Y. S., Cha Y. N., Na H. K., Surh Y. J. (2014): Keap1 cysteine 288 as a potential target for diallyl trisulfide-induced Nrf2 activation. PLoS One 9, e85984 https://doi.org/10.1371/journal.pone.0085984

Kondo N., Nakamura H., Masutani H., Yodoi J. (2006): Redox regulation of human thioredoxin network. Antioxid. Redox. Signal. 8, 1881-1890

https://doi.org/10.1089/ars.2006.8.1881

Kweon M. H., Adhami V. M., Lee J. S., Mukhtar H. (2006): Constitutive overexpression of Nrf2-dependent heme oxygenase- 1 in A549 cells contributes to resistance to apoptosis induced by epigallocatechin 3-gallate. J. Biol. Chem. 281, 33761-33772 https://doi.org/10.1074/jbc.M604748200

Kwon T., Rho J. K., Lee J. C., Park Y. H., Shin H. J., Cho S., Kang Y. K., Kim B. Y., Yoon D. Y, Yu D. Y. (2015): An important role for peroxiredoxin II in survival of A549 lung cancer cells resistant to gefitinib. Exp. Mol. Med. 47, e165 https://doi.org/10.1038/emm.2015.24

Lea M. A. (1996): Organosulfur compounds and cancer. Adv. Exp. Med. Biol. 401, 147-154 https://doi.org/10.1007/978-1-4613-0399-2_12

Li J., Calkins M. J., Johnson D. A., Johnson J. A. (2007): Role of Nrf2-dependent ARE-driven antioxidant pathway in neuroprotection. Methods Mol. Biol. 399, 67-78 https://doi.org/10.1007/978-1-59745-504-6_6

Li L., Sun T., Tian J., Yang K., Yi K., Zhang P. (2013): Garlic in clinical practice: an evidence-based overview. Crit. Rev. Food Sci. Nutr. 53, 670-681 https://doi.org/10.1080/10408398.2010.537000

Liang D., Wu H., Wong M. W., Huang D. (2015): Diallyl trisulfide is a fast $\mathrm{H} 2 \mathrm{~S}$ donor, but diallyl disulfide is a slow one: The reaction pathways and intermediates of glutathione with polysulfides. Org. Lett. 17, 4196-4199

https://doi.org/10.1021/acs.orglett.5b01962

Liu J., Akahoshi T., Namai R., Matsui T., Kondo H. (2000): Effect of auranofin, an antirheumatic drug, on neutrophil apoptosis. Inflammation Res. 49, 445-451 https://doi.org/10.1007/s000110050615

Liu L. L., Yan L., Chen Y. H., Zeng G. H., Zhou Y., Chen H. P., Peng W. J., He M., Huang Q. R. (2014): A role for diallyl trisulfide in mitochondrial antioxidative stress contributes to its protective effects against vascular endothelial impairment. Eur. J. Pharmacol. 725, 23-31 https://doi.org/10.1016/j.ejphar.2014.01.010

Lyakhovich A., Graifer D. (2015): Mitochondria-mediated oxidative stress: Old target for new drugs. Curr. Med. Chem. 22, 3040-3053 https://doi.org/10.2174/0929867322666150729114036 
Mena S., Ortega A., Estrela J. M. (2009): Oxidative stress in environmental-induced carcinogenesis. Mutat. Res. 674, 36-44 https://doi.org/10.1016/j.mrgentox.2008.09.017

Murakami S., Motohashi H. (2015): Roles of Nrf2 in cell proliferation and differentiation. Free Radic. Biol. Med. 88, 168-178 https://doi.org/10.1016/j.freeradbiomed.2015.06.030

Mustacich D., Powis G. (2000): Thioredoxin reductase. Biochem. J. 346, 1-8 https://doi.org/10.1042/bj3460001

Nguyen P., Awwad R.T., Smart D.D., Spitz D.R., Gius D. (2006): Thioredoxin reductases a novel molecular target for cancer therapy. Cancer Lett. 236, 164-174 https://doi.org/10.1016/j.canlet.2005.04.028

O‘Connell M. A., Hayes J. D. (2015): The Keap1/Nrf2 pathway in health and disease: from the bench to the clinic. Biochem. Soc. Trans. 43, 687-689 https://doi.org/10.1042/BST20150069

Padiya R., Banerjee S. K. (2013): Garlic as an anti-diabetic agent: recent progress and patent reviews. Recent Pat. Food Nutr. Agric. 5, 105-127 https://doi.org/10.2174/18761429113059990002

Paine A., Eiz-Vesper B., Blasczyk R., Immenschuh S. (2010): Signaling to heme oxygenase- 1 and its anti-inflammatory therapeutic potential. Biochem. Pharmacol. 80, 1895-1903 https://doi.org/10.1016/j.bcp.2010.07.014

Roder C., Thomson M.J. (2015): Auranofin: repurposing an old drug for a golden new age. Drugs R. D. 15, 13-20 https://doi.org/10.1007/s40268-015-0083-y

Rogakou E. P., Pilch D. R., Orr A. H., Ivanova V. S., Bonner W. M. (1998): DNA double-stranded breaks induce histone H2AX phosphorylation on serine 139. J. Biol. Chem. 273, 5858-5868 https://doi.org/10.1074/jbc.273.10.5858

Silva-Palacios A., Königsberg M., Zazueta C. (2016): Nrf2 signaling and redox homeostasis in the aging heart: A potential target to prevent cardiovascular diseases? Ageing Res. Rev. 26, 81-95 https://doi.org/10.1016/j.arr.2015.12.005

Stefanson A. L., Bakovic M. (2014): Dietary regulation of Keap1/ Nrf2/ARE pathway: focus on plant-derived compounds and trace minerals. Nutrients 6, 3777-3801 https://doi.org/10.3390/nu6093777
Surh Y. J., Kundu J. K., Na H. K. (2008): Nrf2 as a master redox switch in turning on the cellular signaling involved in the induction of cytoprotective genes by some chemopreventive phytochemicals. Planta Med. 74, 1526-1539 https://doi.org/10.1055/s-0028-1088302

Trio P. Z., You S., He X., He J., Sakao K., Hou D. X. (2014): Chemopreventive functions and molecular mechanisms of garlic organosulfur compounds. Food Funct. 5, 833-844 https://doi.org/10.1039/c3fo60479a

Tsai C. Y., Wang C. C., Lai T. Y., Tsu H. N., Wang C. H., Liang H. Y., Kuo W. W. (2013): Antioxidant effects of diallyl trisulfide on high glucose-induced apoptosis are mediated by the PI3K/ Akt-dependent activation of Nrf2 in cardiomyocytes. Int. J. Cardiol. 168, 1286-1297 https://doi.org/10.1016/j.ijcard.2012.12.004

Xu X. H., Li G. L., Wang B. A., Qin Y., Bai S. R., Rong J., Deng T., Li Q. (2015): Diallyl trisufide protects against oxygen glucose deprivation -induced apoptosis by scavenging free radicals via the PI3K/Akt -mediated Nrf2/HO-1 signaling pathway in B35 neural cells. Brain Res. 1614, 38-50 https://doi.org/10.1016/j.brainres.2015.04.014

You S., Nakanishi E., Kuwata H., Chen J., Nakasone Y., He X., He J., Liu X., Zhang S., Zhang B., Hou D. X. (2013): Inhibitory effects and molecular mechanisms of garlic organosulfur compounds on the production of inflammatory mediators. Mol. Nutr. Food Res. 57, 2049-2060 https://doi.org/10.1002/mnfr.201200843

Yun H. M., Ban J. O., Park K. R., Lee C. K., Jeong H. S., Han S. B., Hong J. T. (2014): Potential therapeutic effects of functionally active compounds isolated from garlic. Pharmacol. Ther. 142, 183-195 https://doi.org/10.1016/j.pharmthera.2013.12.005

Zhao X., Sun P., Qian Y., Suo H. (2014): D. candidum has in vitro anticancer effects in HCT-116 cancer cells and exerts in vivo anti-metastatic effects in mice. Nutr. Res. Pract. 8, 487-493 https://doi.org/10.4162/nrp.2014.8.5.487

Received: June 30, 2016

Final version accepted: September 11, 2016

First published online: February 20, 2017 